\section{Lentiviral reporter constructs for fluorescence tracking of the temporospatial pattern of Smad3 signaling}

\author{
Christina H. Stuelten, Anil K. Kamaraju, Lalage M.Wakefield, \\ and Anita B. Roberts \\ National Institutes of Health, Bethesda, MD, USA \\ BioTechniques 43:289-294 (September 2007) \\ doi 10.2144/000112549
}

Canonical TGF- $\beta$ is involved in cell differentiation, tissue maintenance, and wound healing, but also plays a central role in the pathogenesis of diseases such as cancer. Here we describe a lentivirus-based reporter vector system expressing green fluorescent protein (GFP) or red fluorescent protein (RFP) under the control of a Smad3-responsive element $(C A G A)_{12}$ that allows observation of the temporospatial pattern of endogeneous Smad3-mediated signaling on a cellular level. Use of this method will be valuable to identify cells with active Smad3 signaling and investigate the role of endogenous Smad3 signaling in complex systems such as co-cultures in vitro, or in tumors during tumor cell invasion and metastasis in vivo.

The cytokine transforming growth factor $\beta$ (TGF- $\beta$ ) is involved in the regulation of organismal development, cell differentiation, proliferation, apoptosis, tissue maintenance, and wound healing (1). Perturbations of the TGF- $\beta$ system are thought to play a central role in the pathogenesis of diseases such as fibroproliferative disorders and cancer. Therefore, it is important to develop experimental tools that allow visualization of TGF- $\beta$ pathway activation in vitro and in vivo.

TGF- $\beta$ binds to its specific receptor, TGF- $\beta$ receptor II (T $\beta$ RII), which heterodimerizes with and transphosphorylates the TGF- $\beta$ receptor I (TRRI), followed by activation of intracellular signaling cascades. These involve canonical TGF- $\beta$ signaling via T $\beta R I$-dependent phosphorylation of Smad2 and Smad3, which heterodimerize with Smad4, translocate into the nucleus, bind TGF- $\beta$ regulatory elements, and alter gene expression $(2,3)$. Additionally, TGF- $\beta$ can activate non-Smad pathways such as MAPK, $\mathrm{PI} 3 \mathrm{~K} / \mathrm{Akt}, \mathrm{pp} 2 \mathrm{~A} / \mathrm{S} 6$ kinase, and Rho/ Rock $(2,3)$.

The complex regulation of both TGF- $\beta$ activation and downstream signal transduction makes it difficult to determine the activation status of the TGF- $\beta$ pathway. A Smad4-based reporter plasmid has recently been described (4). However, because Smad4 also mediates bone morphogenetic protein (BMP) signaling, this assay lacks specificity. Antibodies specific for phospho-Smad2 have been developed and allow assessment of Smad2 activation by immunohistochemical approaches (5). However, the same approach is problematic for assessing Smad3-mediated signaling in complex situations like co-cultures and tumor activation, where BMP signaling is difficult to exclude because phosphoSmad3 antibodies also recognize the BMP-stimulated phospho-Smad1 and Smad5. A Smad3-based reporter plasmid has been used for reporting signaling in vivo by luciferase, but this approach cannot be used to determine temporospatial distribution of Smad3 signaling at a cellular rather than tissue level $(6,7)$.

TGF- $\beta$ plays a complex dual role as tumor suppressor and metastasis promoter (8), and the balance between Smad 2 and Smad3 or between Smad and non-Smad signaling may be important for determining the outcome. Smad2 has been found to be mutated or deleted in some human cancers, but Smad3 is not, suggesting that these two closely related Smads may play distinct roles in tumorigenesis (9). The role of $\mathrm{Smad} 3$ as a potential therapeutic target in cancer and fibroproliferative disorders makes it highly desirable to identify which cells, in cultures or tissues specifically, have active Smad3 signaling and under what circumstances. Here we describe a method that allows assessment of the spatiotemporal pattern of TGF- $\beta$ signaling via Smad3 in cells and reconstituted tissues on a cellular level.

We have used a lentivirus-based reporter vector system expressing green fluorescent protein (GFP), red fluorescent protein (RFP), or luciferase under the control of a Smad3responsive element (CAGA) ${ }_{12}$ (10) to stably infect human and mouse cells. The (CAGA) $)_{12}$ element was inserted between EcoRI and SpeI sites of a Cop-GFP/RFP lentiviral vector (SBI, Mountain View, CA, USA), and virus was generated with these custom made vectors according to the manufacturer's instructions. In brief, 293T cells $\left(3 \times 10^{6}\right.$ cells $/ 80 \mathrm{~cm}^{2}$ growth area) were cultured in Dulbecco's modified Eagle's medium (DMEM) supplemented with $10 \%$ fetal bovine serum (FBS) overnight, and then transfected with reporter plasmid $(2 \mu \mathrm{g} /$ plate $)$ and packaging plasmid mix $(10 \mu \mathrm{g} /$ plate $)$ using Lipofectamine Plus ${ }^{\mathrm{TM}}$ reagent (Invitrogen, Carlsbad, CA, USA). Medium was replaced with low serum medium $(0.5 \%$ FBS $) 12 \mathrm{~h}$ later. Viruscontaining supernatants were collected after 24 and $48 \mathrm{~h}$ and filtered $(0.45 \mu \mathrm{m})$ to remove cell debris. For lentiviral infection, cells were seeded at a density of $5 \times 10^{5}$ cells $/ 80 \mathrm{~cm}^{2}$ growth area and incubated with lentiviral supernatant $(3 \mathrm{~mL} /$ plate) supplemented with Polybrene $^{\circledR}$ (4 $\mu \mathrm{g} / \mathrm{mL}$; Sigma-Aldrich, St. Louis, MO, USA) for $24 \mathrm{~h}$.

We found that a variety of cell lines including mouse embryonic and dermal fibroblasts, mouse mammary cancer cells (4T07), human breast epithelial (MCF10A), and tumor cells (MCF10CA1h, MCF10CA1a) (11-13) could be infected with virus constitutively expressing GFP with high efficiency, although GFP expression was generally higher in human as compared with mouse cells (Figure 1A). Constitutive GFP expression in stably infected cells persisted for at least 20 passages and was not altered 


\section{Benchmarks}

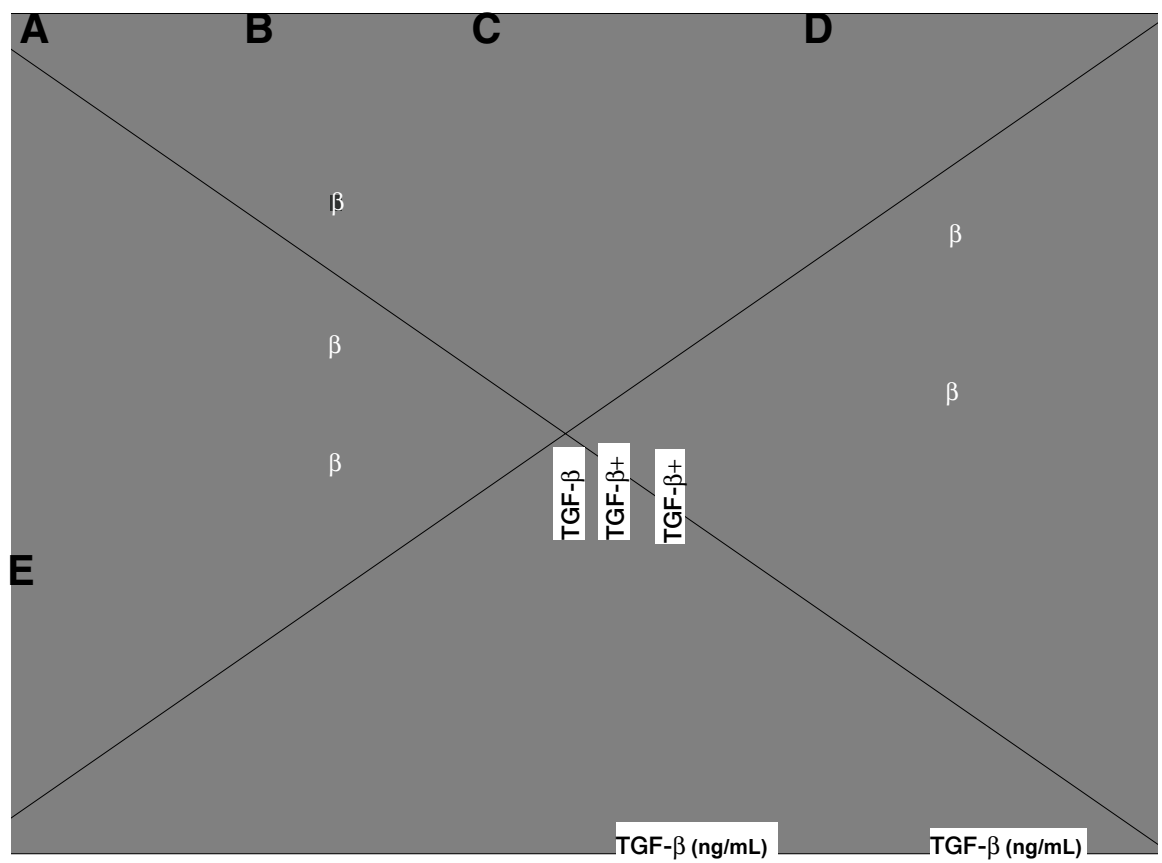

Figure 1. (CAGA) $)_{12}$-mediated green fluorescent protein (GFP) expression levels report transforming growth factor $\beta$ (TGF- $\beta$ )-induced Smad3 signaling but not Smad2 signaling or non-canonical TGF- $\beta$ signaling in a variety of cell lines and in a dose-dependent manner. (A) GFP expression in mouse embryonic fibroblasts (MEFs), mouse breast cancer cells (4T07), and human breast cancer cells (MCF10CA1h) after infection with a constitutively GFP expressing control vector. (B and C) The (CAGA) 12 vector specifically reports Smad3-mediated signaling. Smad3mediated GFP expression was induced in MCF10A cells (B and C) and MCF10CA1h cells (C) by stimulation with TGF- $\beta$, and abolished by addition of the ALK5 kinase inhibitor SB431542, whereas the p38 kinase inhibitor SB203580 did not affect TGF- $\beta$-induced GFP expression [negative control: dimethyl sulfoxide (DMSO)]. Green fluorescence of the confluent cell cultures was quantified from monochromatic images by using the imaging program Metamorph and Excel. (D) TGF- $\beta$-induced GFP expression in Smad2 knockout (S2KO) fibroblasts but not in Smad3 knockout fibroblasts (S3KO). (E and F) Smad3-mediated GFP and luciferase expression levels correlate with the concentration of TGF- $\beta$ used for stimulating cells. MCF10CA1h cells were infected with $(\mathrm{CAGA})_{12}$-GFP- or (CAGA) $)_{12}$-luciferase-expressing vector. GFP and luciferase expression levels were monitored $24 \mathrm{~h}$ after addition of TGF- $\beta$. Green fluorescence of the confluent cell cultures was quantified from monochromatic images shown in panel $\mathrm{E}$ by analyzing brightness of the signal using the imaging program Metamorph and Excel. (F, left graph) Luciferase activity was assessed using the Dual Luciferase ${ }^{\circledR}$ kit (Promega, Madison, WI, USA) according to the manufacturer's instructions, and data were analyzed using Microsoft Excel (F, right graph). Scale bars, $200 \mu \mathrm{m}$.

by stimulation of these cells with TGF- $\beta$ (data not shown). To investigate specificity for Smad3 signaling versus Smad2 signaling and sensitivity of $(\mathrm{CAGA})_{12}$-driven GFP expression, we stimulated serum-starved (overnight) HepG2 (0.5\% FBS), MCF10A, and MCF10CA1h $(0.2 \%$ horse serum $)$ with TGF- $\beta(2 \mathrm{ng} / \mathrm{mL})$ alone or 30 min after addition of small-molecule inhibitors, and GFP expression levels were monitored $24 \mathrm{~h}$ later. TGF- $\beta$ induced GFP expression was inhibited by the ALK5 (T $\beta R I)$ kinase inhibitor SB431542 $(5 \mu \mathrm{M})$, but not the structurally related p38 kinase inhibitor SB203589 (10 $\mu$ M; Figure 1, B and C), the MEK/Erk inhibitor PD98059 (25 $\mu \mathrm{M})$, or the ROCK inhibitor Y27632 ( $20 \mu \mathrm{M}$; data not shown). TGF- $\beta$ (2 $\mathrm{ng} / \mathrm{mL}$ ) induced GFP expression in overnight serum-starved $[0.5 \%$ fetal calf serum (FCS)] Smad2 knockout fibroblasts within $24 \mathrm{~h}$, but not in Smad3 knockout fibroblasts (Figure 1D). These results prove that the construct indeed responds to TGF- $\beta$ in a Smad3-dependent manner, and does not respond to Smad2- or nonSmad-mediated TGF- $\beta$ signaling. TGF- $\beta$ stimulation of GFP expression in overnight serum-starved $(0.2 \%$ horse serum) MCF10CA1h cells was dosedependent between $0.02 \mathrm{ng} / \mathrm{mL}$ and $5 \mathrm{ng} / \mathrm{mL}$ (Figure 1, E and F) for both $(\mathrm{CAGA})_{12}$-mediated GFP and lucif- erase expression. However, the GFP reporter gave a better signal-to-noise ratio than the luciferase reporter in the low TGF- $\beta$ concentration range (Figure $1 \mathrm{~F})$, suggesting that the fluorescence approach has advantages for reporting on the low levels of TGF- $\beta$ that are likely to occur endogenously in vivo. Infection of cells with a (CAGA) ${ }_{12-}$ RFP construct yielded similar results (data not shown), thus allowing us to simultaneously study endogenous Smad3 signaling in more than one cell type. We employed (CAGA) ${ }_{12}$ GFP-infected MCF10CA1a cells and (CAGA) $)_{12}$-RFP-infected mouse fibroblasts to track temporospatial $\mathrm{Smad} 3$ signaling in a co-culture system (12) (Figure 2). $5 \times 10^{5} \mathrm{MCF} 10 \mathrm{CA} 1 \mathrm{a}$ cells and $5 \times 10^{5}$ fibroblasts were plated in $10 \mathrm{~mL}$ co-culture medium $(46.25 \%$ DMEM, 46.25\% DMEM F12, 5\% FBS, $2.5 \%$ horse serum) in a $100-\mathrm{mm}$ tissue culture dish and incubated at 5\% $\mathrm{CO}_{2}, 37^{\circ} \mathrm{C}$ in a humidified atmosphere. In contrast to homotypic cultures in which very little activation of $\mathrm{Smad} 3$ was observed, co-cultures showed activated Smad3 signaling in both cell types, tumor cells, and fibroblasts, with a maximum of Smad3-mediated RFP/GFP expression at 2 days (Figure 2A). The ALK5 inhibitor SB431542 $(5 \mu \mathrm{M})$ but not dimethyl sulfoxide (DMSO) (control) abolished Smad3driven GFP expression in co-cultures, confirming that TGF- $\beta$ signaling through this receptor contributes to Smad3 signaling in co-cultures (Figure 2B). We next explored if the reporter system can be used for in vivo applications. (CAGA) $)_{12}$-GFP-infected MCF10CA1a cells $\left(5 \times 10^{5}\right.$ cells $)$ and (CAGA) $)_{12}$-RFP-infected fibroblasts (5 $\times 10^{5}$ cells) were coinjected into the mammary fat pad IV/V of athymic nude mice (nu/nu; 8-week-old), and the tumors that developed were excised after 13 days. Tumors were then cut into cross-sections using a razor blade. Sections were flipped onto a coverglass, covered with Dulbecco's phosphate-buffered saline (DPBS) containing Hoechst 33342, and used for confocal microscopy. In this xenograft model, (CAGA) 12 -mediated GFP and RFP expression was seen in a subset of tumor cells and fibroblasts (Figure 2C). This indicates that this reporter system 


\section{Benchmarks}
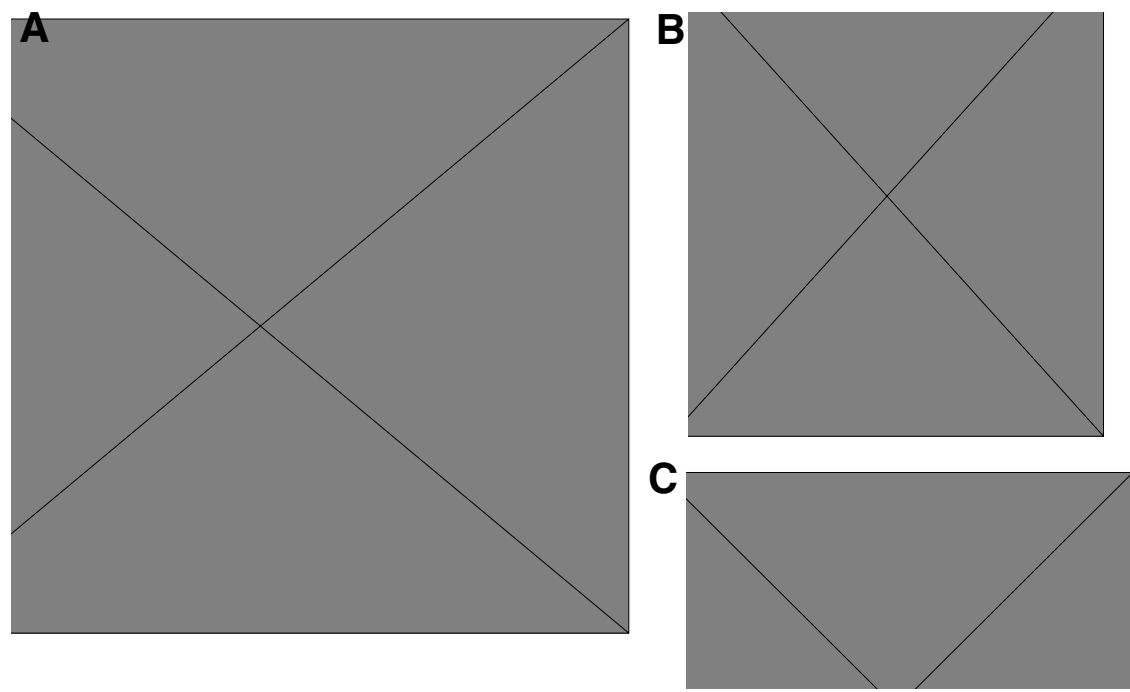

Figure 2. (CAGA) $)_{12}$-green fluorescent protein (GFP) and (CAGA) $)_{12}$-red fluorescent protein (RFP)infected cells report endogeneous Smad3 signaling in co-cultures of human breast cancer cells (MCF10CA1a) and mouse dermal fibroblasts (DFs), and in xenograft tumors. (A) Tumor cells (MCF10CA1a) stably infected with (CAGA) $)_{12}$-GFP and mouse DFs stably infected with (CAGA) $)_{12}$-RFP were cultured separately or co-cultured (DF X MCF10CA1a) and then examined at the indicated times. Scale bar, $80 \mu \mathrm{m}$. (B) Addition of the ALK5 inhibitor SB431452 to the co-culture abolished increased GFP expression in co-cultures of (CAGA) ${ }_{12}$-GFP-infected MCF10CA1a cells and dermal fibroblasts, indicating that Smad3 activation in this culture is mediated by TGF- $\beta$. Scale bar, $200 \mu \mathrm{m}$. (C) In xenograft tumors of $(\mathrm{CAGA})_{12}$-GFP-infected MCF10CA1a cells and (CAGA) $)_{12}$-RFP-infected fibroblasts, (CAGA) ${ }_{12}$-driven GFP expression in tumor cells was seen at the tumor margin close to the skin (left). Although generally little connective tissue is found in xenograft tumors, we observed (CAGA) ${ }_{12}$-driven RFP expression in some areas of the tumor (right), indicating that both tumor cells and fibroblasts have activated Smad3 signaling in the xenografted tumors. GFP, green; RFP, red; Hoechst 33342 (nuclei), blue. Scale bar, $200 \mu \mathrm{m}$.

has the sensitivity to report on endogeneous TGF- $\beta$ signaling in vivo.

Our data demonstrate that $(\mathrm{CAGA})_{12}$-driven GFP/RFP expression is a powerful and sensitive tool to observe the spatiotemporal pattern of endogeneous Smad3 signaling at the cellular level not only in vitro, but also in vivo, as for example in different areas of tumors or during tumor cell invasion and metastasis. This approach should greatly enhance our knowledge about activation of TGF- $\beta$ signaling cascades in complex biological systems.

\section{ACKNOWLEDGMENTS}

C.H.S. and A.K.K. contributed equally to this work. A.B.R. died on May $26^{\text {th }}$, 2006. The authors very much appreciated the help of Tatiana Karpova and James McNally with quantification of images. Smad2 knockout and the corresponding wild-type fibroblasts were a gift from Erwin Bottinger.

\section{COMPETING INTERESTS}

\section{STATEMENT}

The authors declare no competing interests.

\section{REFERENCES}

1. Roberts, A.B., F. Tian, S.D. Byfield, C. Stuelten, A. Ooshima, S. Saika, and K.C. Flanders. 2006. Smad3 is key to TGF-betamediated epithelial-to-mesenchymal transition, fibrosis, tumor suppression and metastasis. Cytokine Growth Factor Rev. 17:19-27.

2. Massague, J. 2000. How cells read TGF-beta signals. Nat. Rev. Mol. Cell Biol. 1:169-178.

3. Wakefield, L.M. and A.B. Roberts. 2002. TGF-beta signaling: positive and negative effects on tumorigenesis. Curr. Opin. Genet. Dev. 12:22-29.

4. Kang, Y., W. He, S. Tulley, G.P. Gupta, I. Serganova, C.R. Chen, K. ManovaTodorova, R. Blasberg, et al. 2005. Breast cancer bone metastasis mediated by the Smad tumor suppressor pathway. Proc. Natl. Acad. Sci. USA 102:13909-13914.

5.Xie, W., J.C. Mertens, D.J. Reiss, D.L. Rimm, R.L. Camp, B.G. Haffty, and M. Reiss. 2002. Alterations of Smad signaling in human breast carcinoma are associated with poor outcome: a tissue microarray study. Cancer Res. 62:497-505.

6. Lin, A.H., J. Luo, L.H. Mondshein, P. ten Dijke, D. Vivien, C.H. Contag, and T. Wyss-
Coray. 2005. Global analysis of Smad2/3dependent TGF-beta signaling in living mice reveals prominent tissue-specific responses to injury. J. Immunol. 175:547-554.

7. Luo, J., A.H. Lin, E. Masliah, and T. WyssCoray. 2006. Bioluminescence imaging of Smad signaling in living mice shows correlation with excitotoxic neurodegeneration. Proc. Natl. Acad. Sci. USA 103:18326-18331.

8. Roberts, A.B. and L.M. Wakefield. 2003. The two faces of transforming growth factor beta in carcinogenesis. Proc. Natl. Acad. Sci. USA 100:8621-8623.

9. Bierie, B. and H.L. Moses. 2006. TGF-beta and cancer. Cytokine Growth Factor Rev. 17:29-40.

10. Piek, E., U. Westermark, M. Kastemar, C.H. Heldin, E.J. van Zoelen, M. Nister, and P. ten Dijke. 1999. Expression of transforming-growth-factor (TGF)-beta receptors and Smad proteins in glioblastoma cell lines with distinct responses to TGF-beta1. Int. J. Cancer 80:756-763.

11. Piek, E., W.J. Ju, J. Heyer, D. EscalanteAlcalde, C.L. Stewart, M. Weinstein, C. Deng, R. Kucherlapati, et al. 2001. Functional characterization of transforming growth factor beta signaling in Smad2- and Smad3-deficient fibroblasts. J. Biol. Chem. 276:19945-19953.

12. Stuelten, C.H., S.D. Byfield, P.R. Arany, T.S Karpova, W.G. Stetler-Stevenson, and A.B. Roberts. 2005. Breast cancer cells induce stromal fibroblasts to express MMP-9 via secretion of TNF- $\{$ alpha $\}$ and TGF- $\{$ beta $\}$ J. Cell Sci. 118:2143-2153.

13. Tang, B., M. Vu, T. Booker, S.J. Santner, F.R Miller, M.R. Anver, and L.M. Wakefield. 2003. TGF-beta switches from tumor suppressor to prometastatic factor in a model of breast cancer progression. J. Clin. Invest. 112:1116-1124.

Received 12 December 2007; accepted 23 July 2007.

Address correspondence to Christina H. Stuelten, Cell and Cancer Biology Branch, National Cancer Institute, National Institutes of Health, 37 Convent Drive, Room 1042, Bethesda, MD 20892-4254, USA.e-mail: chrisstu@mail.nih.gov

To purchase reprints of this article, contact: Reprints@BioTechniques.com 